\title{
Las Constituciones de Anderson en España
}

\section{The Constitutions of Anderson in Spain}

\author{
Pere Sánchez Ferré \\ Doctor en Historia Moderna y Contemporánea, Universidad de Barcelona. Profesor de la Universidad de \\ Barcelona. Miembro fundador del Centro de Estudios Históricos de la Masonería Española. Correo \\ electrónico: peresf19@gmail.com
}

DOI: http://dx.doi.org/10.15517/rehmlac.v8i2.18162

Fecha de recibido: 13 de julio de 2016 - Fecha de aceptación: 3 de septiembre de 2016

Palabras clave

Masonería; James Anderson; Constituciones masónicas de 1723; España; doctrinas masónicas

\section{Keywords}

Freemasonry; James Anderson; Masonic Constitutions of 1723; Spain; Masonic Doctrines

\section{Resumen}

Las Constituciones de Anderson, texto fundacional de la masonería moderna, pasó por el siglo XIX casi ignorado por los hermanos españoles, indiferentes a todo lo que procedía de la masonería inglesa y, por lo general, reacios a los discursos espiritualistas y legendarios de la Orden. Hubo que esperar al siglo XX (1936) para que se publicara la edición en español, a la que se añadió algunos antiguos Landmarks, aunque su publicación llegaba tarde, pues ese mismo año estallaba la guerra civil en España.

\begin{abstract}
The Constitutions of Anderson, the founding text of modern Freemasonry, went through the nineteenth century almost ignored by the Spanish brothers, who were generally indifferent to everything that came from English Freemasonry and usually reluctant to embrace the spiritualist discourses and legendary speeches of the Order. The text was not widely circulated until the twentieth century (1936) production of the Spanish edition, to which was added some of the antiquated Landmarks. However, its publication appeared too late, because that same year civil war broke out in Spain.
\end{abstract}

\section{Introducción. La masonería es España}

A partir de la Revolución de 1868 y con el advenimiento del clima de libertades que trajo la Gloriosa, las logias se multiplicaron en España y la vida masónica tomó un auge sin precedentes. Gracias a esta expansión, apareció un número importante de revistas masónicas de circulación interna, así como bastantes obras de historia de la masonería, textos doctrinales, además de manuales, reglamentos, liturgias, libros de rituales, constituciones masónicas y otras obras de uso interno. Mucha de esta literatura se distribuía y vendía en las librerías, con lo que los curiosos e interesados en la Orden de la escuadra y el compás tuvieron acceso a mucho de lo que hasta entonces había pertenecido al ámbito interno de la masonería. 
Las obras dedicadas a la historia de la masonería publicadas durante el último tercio del siglo XIX carecen normalmente de rigor histórico, y convierten la Orden en el sujeto mayor de la historia de Occidente. Así, la masonería es presentada como la autora de la Ilustración, de la Revolución francesa o de las revoluciones liberales decimonónicas, lo cual no hace más que dar argumentos a la Iglesia católica, su secular enemiga, que la acusa precisamente de aquello que los masones reivindican con insistencia.

Pero al margen del polemismo decimonónico alimentado por la hagiografía masónica y los libelos clericales, se publicaron algunas obras de interés, como El Consultor del masón, (1883) del cubano Aurelio Almeida, ya citado, o la Historia general de la masonería (1883), firmada por Danton, así como las de Eduardo Caballero de Puga, Mariano Figueroa Ríos y Nicolás Díaz y Pérez, todos ellos masones ${ }^{1}$. A esa primera infancia de la cultura masónica en nuestro país colaboró significativamente la obra financiada por el masón, republicano catalanista y librepensador, Rosend Arús: el Diccionario enciclopédico de la masonería, editado primero en La Habana, (1883) y posteriormente en Barcelona, en 1891. Esta obra es el mejor exponente de la cultura masónica que, si bien en los países anglosajones ya está muy consolidada, hace sus primeros pasos en esta nueva España precariamente democrática.

Sin embargo, ni entonces ni posteriormente las Constituciones de J. Anderson texto fundacional de la masonería moderna o especulativa- mereció el particular interés de las obediencias masónicas ni de sus miembros, como lo demuestra el hecho de que no fueran publicadas hasta 1936. Es significativo que el citado Diccionario enciclopédico de la masonería -muy influido por la cultura masónica francesa- despache con catorce líneas a James Anderson, mientras dedica más de una página a glosar la figura del también inglés y masón Elías Ashmole (1617-1692), a quien considera “el verdadero padre de la Masonería actual", siguiendo las tesis de algunos autores masones franceses de prestigio en la época, como François Favre y Jean Marie Ragon, este último muy traducido al español, cuyas obras son una buena muestra del esoterismo de izquierdas que imperaba en la masonería francesa de mediados del siglo XIX.

Durante el primer tercio del siglo XX disminuye el número de publicaciones -como el de masones- y no aparecen obras de interés, a excepción de la labor llevada a cabo por Pedro González Blanco en la revista masónica Latomia, de Madrid, que durante la Segunda República realizó una tarea sin precedentes, divulgando un tipo de cultura masónica hecha con rigor y alejada ya completamente de las deformaciones propias del pasado siglo. Algunos de sus contenidos tenían claras resonancias teosóficas, lo cual era lógico, puesto que los partidarios de la ortodoxia y la tradición masónicas eran teósofos o basaban sus argumentos en un esoterismo y una espiritualidad muy próximos a los de la teosofía.

\footnotetext{
${ }^{1}$ José Antonio Ferrer Benimeli, Bibliografia de la masonería (Madrid: FUE, 1978).
} 


\section{Las Constituciones en el siglo XIX}

En España, la única noticia que tenemos de la edición de las Constituciones anteriores a la de 1936 es la que aparece en el Anuario Masónico de Eduardo Contreras de Diego: Constituciones de la antigua sociedad de Libres y Aceptados masones, "publicada por acuerdo y autoridad de la Gran Logia Unidad de Inglaterra, traducción del hermano Knox, Grado 30, Madrid, 1877"2. Sin embargo, no tenemos otra referencia de esta edición que la dada por dicho Anuario, que contiene un número considerable de obras, así como de prensa masónica. Por lo tanto, no sabemos si se trata de una edición completa o de una parte de ella.

Como he dicho, el texto de Anderson no tendrá demasiada suerte a lo largo del siglo XIX, pues será casi ignorado por los hermanos peninsulares, indiferentes por lo general a todo lo que procedía de la masonería inglesa. Incluso entre los grupos más tradicionales pro-ingleses, como el llamado "G. O. de Pérez" (Gran Logia Simbólica de España) ${ }^{3}$, o el que en Cataluña se agrupó una temporada en torno a la revista El Mallete, órgano oficioso de la logia barcelonesa "Silencio". Esta logia denunciaba el furor publicitario que se apoderó de la masonería de su tiempo, pues andaban por las librerías del país:

tanto libros y folletos, rituales y liturgias, en los que además de dar a conocer a todo el mundo signos y señales, palabras y ceremonias, han sido escritos, no con criterio propio de la Orden, no inspirándose en sus principios fundamentales, sino en la opinión particular y propia de cada autor. (...) Añadamos a esto la divulgación de cosas que debieran quedar reservadas exclusivamente para los trabajos masónicos...

No obstante, parece que ciertos secretos y documentos no se habían dado aún a la imprenta, pues el quincenal masónico puntualiza:

Afortunadamente $-\mathrm{y}$ de esto nos congratulamos mucho- tanto como se ha escrito $y$ publicado, las verdaderas liturgias del Rito escocés antiguo se han salvado en su parte más esencial de ese furor de publicación que ha acometido a muchos masones". Aquí el anónimo autor del artículo puntualiza que los rituales que se pueden encontrar impresos no son los del auténtico "Rito escocés antiguo", ya que éstos "no se han dado nunca a la luz, por lo menos que sepamos..."4.

\footnotetext{
${ }^{2}$ Eduardo Contreras de Diego, Anuario Masónico Universal para el año de 1886 (Madrid, 1885), 181. Se trata del Anuario del G. O. de España, en la época que Manuel Becerra era su gran maestro.

${ }^{3}$ Véase Boletín Oficial de la Masonería Regular de España 12 (15 de mayo de 1884): 6. Desde abril de 1875 no se había publicado dicho Boletín.

${ }^{4}$ El Mallete 31 (15 de febrero de 1883): 1-2. Por otra parte, en 1786 se publicó en Salamanca un pliego de siete páginas titulado BASES e Institutos secretos y verdaderos de la Orden de Antiguos, Libres y aceptados masones. Grandes Constituciones del Rito A3ntiguo Escocés aceptado: figura en la Bibliografía de la Masonería de Ferrer Benimeli, 157.
} 
Sin embargo, la pasión por publicarlo todo no propició una edición española de las Constituciones de Anderson. ¿Por qué razón? Creo que en gran parte porque en Francia no se había prestado aún atención al texto fundacional de la masonería especulativa, y aquí la masonería seguía con aplicación -y a menudo devoción- los pasos del vecino francés; como en el campo de la cultura, también en el masónico se seguían los dictados franceses, particularmente en Cataluña.

Curiosamente, todos -al menos hasta 1877- invocaban en sus tenidas al Gran Arquitecto del Universo, término acuñado en las Constituciones, pero las ignoraban... Igualmente, todos escuchaban alusiones a la fórmula escrita por Anderson y sus colaboradores acerca de la creencia en Dios: el masón "no será jamás un estúpido ateo ni un libetino irreligioso" y deberá "profesar aquella religión que todo hombre acepta"5. Con todo, casi nadie se interesó en nuestro país en conocer la obra de Anderson hasta finales del siglo XIX.

En Francia, la ignorancia o indiferencia hacia el texto de Anderson y Désaguliers era tal que incluso en los largos y agrios debates en el seno del G. O. de Francia en torno a la obligatoriedad de creer en Dios, no hubo una sola alusión a Las Constituciones o a sus autores. Daniel Ligou señala que el interés de los masones franceses por Anderson y sus Constituciones nació en el siglo XX. Así ocurrió también en el campo del antimasonismo profesional, pues el núcleo de monseñor Jouin y la Revue International des Societés Secrètes utilizaron el texto de 1723 para denunciar las maniobras protestantizadoras de los masones de la G. L. Unida de Inglaterra para inclinar a la Orden hacia el teísmo y traicionar el espíritu indiscutiblemente católico de las Old Charges, es decir, de la masonería operativa medieval ${ }^{6}$. Curiosamente, este argumento fue después esgrimido por René Guénon, en 1926, quien en la revista Regnabit denunció asimismo las turbias y antitradicionales maniobras del modernismo protestante para hacer desaparecer el origen y el contenido católico de la masonería medieval en nueva singladura de la Orden, con lo cual la existencia de la masonería moderna o especulativa descansaba de hecho en "una desviación"7.

En España, el Diccionario Enciclopédico de la Masonería, (La Habana, 1883 y Barcelona 1891, redactado por Luis Ricardo Fors y Lorenzo Frau Abrines ${ }^{8}$ y dirigido por Rosendo Arús) dedica veinte palabras al "Doctor Désaguliers", en las que el lector no se

\footnotetext{
5 "De Dios y de la religión", La Constitución de 1723 proyectada por J. Anderson..., ed. y notas de Pere Sánchez Ferré (Barcelona: Ed. Alta Fulla, Barcelona, 1998), 76.

${ }^{6}$ Daniel Ligou, Constitutions d'Anderson (París: Edimaf, 1992), 14-16.

${ }^{7}$ René Guénon, Études sur la Franc-maçonnerie et le Compagnonnage (París: Éd. Traditionelles, 1978), vol. II, 72-73.

${ }^{8}$ Luis Ricardo Fors era grado $33^{\circ}$, abogado de profesión y militaba en el republicanismo. Residió en La Habana, donde fundó tres periódicos: "El Progreso", "El Argentino" y "El Autonomista Español". La primera edición del Diccionario está firmada por él, y la de Barcelona, por L. Frau Abrines. Lorenzo Frau Abrines, simbólico "Leónidas", como el anterior era miembro de la logia barcelonesa "Constancia" y grado 33; fue uno de los fundadores de la G. L. Simbólica Regional Catalana Balear.
} 
entera de otra cosa más que colaboró con J. Anderson. A éste le dedica algo más de espacio: unas pocas líneas, donde se dice que era doctor en filosofía, predicador presbiteriano, y que recogió y compiló los Antiguos Preceptos y Reglamentos Generales y que "La obra capital recopilada por Anderson titulóse Book of Constitutions (Libro de las Constituciones)". Notemos que no es ese su título exacto, sino The Constitutions of the Free-Masons. Como vemos, la información de que disponían los redactores del Diccionario (o el interés por el personaje) era muy escasa. Sin embargo, Lorenzo Frau se refiere en su Introducción a la quema en Londres, en 1720, de "los archivos de las antiguas Confraternidades de los Constructores", que achaca a la fuerte prevención que se tuvo siempre en la masonería a publicar documentos internos de la Orden. Pero Frau y Fors no estaban de acuerdo con tal prevención. No podía ser de otro modo, puesto que ellos mismos estaban publicando en el Diccionario un resumen de los rituales de todos los grados y sistemas masónicos.

Aunque no se le presta especial atención al texto inglés, en la "Historia de la masonería" que el Diccionario incluye en su Suplemento, escrita por el historiador alemán J. G. Findel en 1861, se reproducen, en cuatro páginas, varios fragmentos de las Constituciones $^{9}$ : el dedicado a Dios y la religión, donde se dice que el masón no será un "ateo estúpido", los que se ocupan de los aprendices, compañeros, maestros e inspectores, el consagrado al reglamento y a la conducta de los hermanos.

Por otra parte, en las voces del Diccionario de R. Arús dedicadas a personajes presentes en las historias legendarias de los textos masónicos antiguos o en las Constituciones de Anderson, como Adán (el primer vocablo del mismo), se ignora que figura en las Constituciones o en las Old Charges como el primer masón, aunque señala que en el Rito de Misraim "se enseña que la creación de la Orden masónica" es obra de Adán y Eva y presidida "por Dios mismo, cuando la Logia en que éstos trabajaban se hallaba situada en el paraíso terrestre"10. A Noé se le dedica casi cuatro páginas, en las que se explica con detalle la epopeya noaquita, desde su nacimiento hasta su muerte, siguiendo siempre las fuentes bíblicas. Y si bien no consigna que este patriarca está presente tanto en las Old Charges como en las Constituciones de 1723, sí se hace referencia a los aspectos simbólicos del personaje como uno de los posibles fundadores de la masonería. Sin embargo, estas referencias a los orígenes religiosos o legendarios de la Orden se aborda no sin un manifiesto reparo e incomodidad, puesto que los aires positivistas ya habían penetrado en una parte importante de la nómina masónica. Incluso les cuesta admitir que los orígenes históricos de la masonería estén en Egipto y el pueblo judío, como afirman ciertos autores, a lo que añaden: "por muy absurdo que pueda parecer a algunos",11.

\footnotetext{
${ }^{9}$ Historia General de la Orden Franmasónica (La Habana, 1883), vol. III, pp. 44-48.

${ }^{10}$ Diccionario enciclopédico de la masonería, voz "Noé". Este patriarca figura en los rituales de varios Ritos masónicos, así como en diversos grados superiores del escocismo.

${ }^{11}$ Diccionario enciclopédico de la masonería, voz "Noé".
} 
También se hace eco el Diccionario de que ciertos historiadores "sostienen, aunque tímidamente, una opinión poco conocida, que fija la cuna de la Francmasonería como originaria de la construcción del Arca". Quien esto escribe, sin embargo, apunta a continuación que dichas teorías no son nada serias, y se apoya en un autor masón francés llamado Boubé para desautorizar aquello que la erudición de la época aconseja insertar en la voz "Noé", pero que no casa bien con el talante racionalista y científico que aspira a tener la obra. Las palabras del literato galo vienen en auxilio de la verdad científica:

Si entre los masones, (...) los hay que gustan perderse en la oscuridad de su origen, si hay otros que se enorgullecen de contar cincuenta y ocho siglos, es porque, persuadidos, como la mayor parte de las mujeres, de que la juventud nada sustrae al mérito, se quitan gustosas algunos centenares de años y no quieren descender más que de Noé; por más que la verdad no gane nada con su sistema, tampoco hacen al menos ningún daño a la moral ${ }^{12}$.

Aunque los redactores se muestran tolerantes y comprensivos con los hermanos más anclados en el pasado legendario y mítico de la Orden, desde luego no comparten sus principios, pues la ciencia positiva y la historia han demostrado que son falsos. Queda, eso sí, el aspecto simbólico de la leyenda masónica, que se acepta con más o menos facilidad según el talante de cada hermano. El Diccionario alude a ese contenido simbólico diciendo que el "Arca en el cual fue salvado el género humano (...) es el símbolo del alma agitada sobre el mar de pasiones, escapando y salvándose del diluvio de los vicios" ${ }^{\text {"13 }}$.

Pero el racionalismo era todavía joven en la masonería y, de hecho, había penetrado con más dificultad que en otros ámbitos, como el de los republicanos y anarquistas, donde medró el movimiento librepensador, enemigo de todo lo relacionado con la espiritualidad fuese religiosa o esotérica. Por eso el Diccionario puede afirmar sin problemas que los "Misterios persas o de los Magos" tienen 100.00 años de antigüedad, así como que todos los misterios iniciáticos antiguos, desde la India a Egipto y Grecia "parecen tener un enlace directo con la Orden Masónica o Ritos Modernos" (voz "Iniciaciones"). En otro lugar, se dice que los antiguos misterios iniciáticos y sus instituciones tenían como objetivo "perpetuar las primeras tradiciones del género humano" (voz "Isis"). Por lo tanto, los iniciados -hombres superiores al vulgo- habían conservado los conocimientos más antiguos y preciados de la humanidad, su sabiduría iniciativa. Este es el discurso de la masonería decimonónica, que sobrevivirá en parte hasta la actualidad: la Orden es tan antigua como las civilizaciones y ha existido entre los hombres de todas las épocas y culturas con diferentes nombres, pero siempre es masonería, misterio iniciático.

\footnotetext{
${ }^{12}$ Diccionario enciclopédico de la masonería, voz "Noé".

${ }^{13}$ Diccionario enciclopédico de la masonería, voz "Noé".
} 
He aquí lo que se expresa al respecto en el órgano oficial del G. O. Español, en 1903:

Difícil sería fijar una época de origen a la Institución masónica. Desde que en medio de las sociedades, quebrantadas por el desenfreno (...) surgieron hombres pensadores que comprendieron que el destino de la humanidad no era el de precipitarse hacia los abismos del mal, sino progresar en la obra de la reconquista de la palabra perdida que había de devolverles la felicidad, desde aquel momento nació la masonería.

Ella se levantó en la India a la mágica voz de los gimnosofistas; abrió los manantiales del saber en la Etiopía y el Egipto... ${ }^{14}$.

Esta concepción de la masonería y de la historia ha pervivido hasta la actualidad. Así, la Orden sería la única y última heredera de los misterios antiguos en Occidente ${ }^{15}$.

Como es natural, entre los creadores de la historiografía moderna dedicada a la masonería, se abordan sus orígenes legendarios con cierto recelo, y se comprende o se admite con más o menos dificultad y dependiendo siempre del grados de prejuicios de que es víctima cada autor la validez de esa tradición legendaria. A J. G. Findel, por ejemplo, su actividad científica como historiador no le impidió comprender y asimilar lo que era el núcleo medular de la masonería, su contenido filosófico más profundo, de carácter iniciático y esotérico. Por eso comprendió rectamente el texto elaborado por Anderson. He aquí lo que escribió al respecto en su Historia de la Francmasonería, que he citado antes:

La historia de la Francmasonería, como la historia del mundo, tiene su base en la Tradición. Lo que el Hermano Anderson atribuye en las primeras páginas de su 'Libro de las Constituciones a la Historia' (sic) es tan solo la historia de la corporación de constructores tal cual se encuentra en las antiguas constituciones y cuyo carácter tradicional no puede ponerse en duda... ${ }^{16}$.

Findel, que era masón, entiende perfectamente el papel que la "Tradición" desempeña en una sociedad iniciática. Este es un término muy sabiamente escogido para designar aquello que forma parte de los orígenes sagrados de la Orden y que justifica la excelencia de su origen. La Tradición oculta es un saber cifrado que se transmite de edad en edad por las generaciones de masones desde el origen de la humanidad.

Este talante capacitado aún para comprender la mentalidad tradicional lo encontramos también en los autores masones del siglo XIX. Entre los más conocidos en

\footnotetext{
${ }^{14}$ Boletín Oficial del Grande oriente Español 131 (11 de marzo de 1903): 43.

15 René Guénon, que fue masón y perteneció también a otras organizaciones iniciáticas, escribió que el catolicismo y la masonería eran las únicas organizaciones -exotérica y esotérica, respectivamente- realmente tradicionales que subsistían en Occidente.

${ }^{16}$ Suplemento, vol. III, 13-14.
} 
España tenemos a Nicolas Charles des Etangs, erudito masón francés que escribió su obra en la primera mitad de aquel siglo. En su obra Manual del Franc-Masón, traducida al español (Madrid, 1871), compagina los orígenes legendarios de la Orden con la historia y la religión "natural", "religión única, universal e inmutable", con el esoterismo masónico basado en alegorías y símbolos. Aunque no cita las Constituciones, sigue el mismo espíritu antiguo de la Orden, otorgando un lugar privilegiado a las narraciones legendarias de los orígenes, donde la historia y la leyenda conviven sin escándalo. Des Etangs traza en unas cuantas páginas de su Manual para los tres grados simbólicos, lo que él llama el "origen y filiación" de la "mágica y sublime institución". Comienza con la descripción de una humanidad primitiva que no comprende pero que "adora" a Dios, ese "creador, dueño de todo, a quien no podemos definir". Sin embargo, el hombre "se hace injusto y cruel" y atrae "la venganza del Cielo", pero es regenerado y nuestros antepasados "más sabios se establecen en la India (los Brahamanes) e instauran las iniciaciones, como en Egipto, donde se celebraban los misterios de Isis y Osiris. De allí pasan a Grecia por medio de Triptólemo, quien volvió a Eleusis, enseñó a los griegos la agricultura e instauró los misterios "mayores y menores". Como en muchos autores de la época, se sobreentiende que esas escuelas iniciáticas antiguas eran en realidad masonerías con otro nombre, y los grandes personajes de la Antigüedad eran también "masones", como Pitágoras y Salomón, a quien des Etangs concede la mayor importancia, puesto que le considera el fundador de la masonería. Siguiendo una creencia muy extendida en el siglo XIX y también hoy día, basada en los propios rituales de los diversos sistemas masónicos, en los que Salomón desempeña un papel fundamental, el autor francés explica que, después de construir el templo de piedra, Salomón propuso a "los jefes" de los trabajos "edificar moralmente, en honor del Gran Arquitecto del Universo, un templo semejante (...) y los obreros manuales, hombres instruidos y piadosos, se convirtieron en obreros simbólicos, o dicho de otro modo, en sabios que practicaban y enseñaban la moral bajo el velo de la alegoría". Des Étangs añade que Salomón fue quien estableció los tres grados de la masonería simbólica: aprendiz, compañero y Maestro. Finalmente, con la diáspora del pueblo judío, la masonería se expandió por todo el mundo y dichos "masones" hebreos incluso ayudaron a los cristianos cuando fueron perseguidos por Roma ${ }^{17}$.

La narración de des Etangs y otros autores masones podrá parecer hoy fruto de mentalidades antiguas y aún demasiado apegadas a los esquemas tradicionales, pero entonces como ahora todo masón inquieto y deseoso de saber, podrá preguntarse a quién debe dar más credibilidad, a la ciencia histórica o a la Tradición, madre y fuente de las verdades masónicas, es decir, las verdades sagradas, de las que la ciencia profana nada sabe ni nada puede opinar...

\footnotetext{
${ }^{17}$ Manual del Franc-Masón (Madrid, 1871), X-XIX.
} 
Otro autor que respeta la realidad sagrada -si puede hablarse así- de los orígenes legendarios de la Orden es F. T. B. Clavel, cuya obra fue traducida y publicada en español ya en 1847 y 1860. Es una de las pocas que a menudo se refiere a España y a su masonería.

Su libro no goza de prestigio en la actualidad, pues hace demasiadas afirmaciones sin probarlas, es cierto. Nuestro erudito especialista en herejías, don M. Menéndez Pelayo la tildó de "estrafalario"18.

En la historia de Clavel hay, en efecto, mucha imaginación, no obstante, en muchos pasajes no hace más que reproducir los contenidos de los Antiguos Deberes ingleses. Clavel no tiene mentalidad científica, sino simbólica, como muchos de sus hermanos contemporáneos; consciente tal vez de que su libro no puede ser el de un historiador científico, al comienzo del mismo apela a: "la tradición masónica, que no se debe despreciar..."19.

Esta tradición es precisamente su fuente principal cuando se refiere a la historia antigua de la masonería.

La historiografía actual desprecia el texto de Clavel, sin embargo, su aparición fue celebrada por "todos los masones amantes del progreso y de la ilustración", según palabras del Diccionario enciclopédico de la masonería. Quien sí lo censuró fue el Gran Oriente de Francia, pues le pareció demasiado indiscreto publicarlo ${ }^{20}$.

Clavel dedica poco más de una página a la confección y publicación de las Constituciones de Anderson y Desaguliers y escribe que gracias a los cambios experimentados por la Orden a partir de 1717, ésta "descansó sobre bases sólidas y su prosperidad fue cada vez más en aumento" ${ }^{21}$. No hay ningún tipo de valoración ni comentario de los contenidos filosóficos o doctrinales de las Constituciones, de las que no reproduce ningún párrafo.

\section{Federico Climent Terrer y las Constituciones de Anderson}

Federico Climent Terrer nació en 1874, en Ulldecona, (prov. de Tarragona) y desde los años veinte compaginó sus actividades teosóficas con las masónicas, como bastantes teósofos de aquella época. Existe constancia documental de su presencia en la logia Inmortalidad, de Barcelona, a partir de 1925, en la que se mantuvo por lo menos hasta 1938; su nombre simbólico era Garfield. La logia Inmortalidad era una de las pocas en que predominaba un cierto esoterismo, gracias a que figuraban en ella otros teósofos que daban

\footnotetext{
${ }^{18}$ Ferrer Benimeli, Bibliografia de la masonería, 72.

${ }^{19}$ F. T. B. Clavel, Historia de la Francmasonería (Madrid: Ed. El Museo universal, 1984), 4. Es la edición que he usado.

${ }^{20}$ Diccionario enciclopédico de la masonería, "Introducción".

${ }^{21}$ Diccionario enciclopédico de la masonería, 26.
} 
a esta logia un carácter espiritualista ${ }^{22}$, en medio de una masonería entregada mayoritariamente a la causa del materialismo cientifista y de la política republicana. Ya en 1925 Climent Terrer ostenta el cargo de Orador de la logia, que también desempeñó en 1930, 1932 y 1938. Pertenecía asimismo a un Capítulo de la masonería Filosófica (grados superiores del Rito Escocés Antiguo y Aceptado), pues en 1931 era grado $18^{\circ}$ (Caballero Rosacruz). Por otra parte, Climent Terrer fue uno de los masones que encabezó una escisión en el seno de la Gran Logia Española, de la que nació una efímera Gran Logia Unida, obediencia de la que fue Gran Orador, hasta que dicha organización se integró en la federación catalana del Gran Oriente Español ${ }^{23}$.

Cuando en 1917, el destacado teósofo Mario Roso de Luna fue iniciado en la logia masónica Isis y Osiris, de Sevilla ${ }^{24}$, no pocos teósofos de toda España también ingresaron en la masonería, creyendo probablemente que ésta era un campo apropiado tanto para hacer proselitismo de sus doctrinas, como también porque existían no pocas afinidades entre los principios filosóficos de una y otra organización. Ambas, en definitiva, eran claros exponentes de la tradición iniciática que aún pervivía en Occidente, con más o menos adulteraciones.

La presencia de hermanos teósofos pronto se hizo sentir en las logias y su influencia se tradujo, tanto en el interior de los templos como en la prensa de la Orden, en la defensa de los principios propiamente iniciáticos y tradicionales de la masonería, frente a la corriente masónica que defendía la supresión del ritual o de la creencia en Dios, es decir, en el Gran Arquitecto del Universo, por considerarlo regresivo y anacrónico.

Como en el siglo XIX, la masonería española siguió estando muy politizada, pero ello no supuso ningún inconveniente para los teósofos que ingresaron en ella, puesto que compaginaban sin problemas el activismo político con las prácticas esotéricas. En la vida profana eran republicanos y de izquierdas; en la masónica, partidarios de la ortodoxia y de la tradición iniciática.

F. Climent Terrer compaginó todo ello con otras actividades, como la de traductor. Estuvo vinculado a la familia de teósofos Maynadé, fundadores de la editorial con este mismo nombre, que tantas obras de esoterismo dio a conocer al público de habla hispana en el primer tercio del siglo XX. En 1911 y 1912 respectivamente, la Biblioteca Orientalista de Ramón Maynadé publicó dos obras fundamentales de H. P. Blavatsky: La Doctrina secreta, e Isis sin Velo, ésta última, verdadera biblia del teosofismo, en cuya traducción colaboró Climent Terrer junto con otros teósofos.

\footnotetext{
${ }^{22}$ Los teósofos decimonónicos fueron los primeros en hablar de la New Age, que hoy se ha convertido en un pseudoespiritualismo mercantilista. Sobre el teosofismo, véase la obra de Guénon, El Teosofismo (Barcelona: Ed. Obelisco, 1989).

${ }^{23}$ Sánchez Ferré, La maçoneria a la societat catalana del segle XX 1900-1947 (Barcelona: Ed. 62, 1993), cap. V.

${ }^{24}$ Sobre este personaje, véase Esteban Cortijo, Mario Roso de Luna (Diputación Prov. de Badajoz, 1992).
} 
Paralelamente a sus actividades masónicas, escribía en la prensa teosófica regularmente, y suponemos que estaba integrado en una de las organizaciones teosóficas de la época. Lo que no cabe duda es que desempeñaba un papel importante en su seno, puesto que en 1933 era el director de la revista Teosofía, editada en Barcelona, continuadora de El Loto Blanco y Sofía, éste último, órgano oficial de la Sociedad Teosófica Española.

Poco sabemos de sus actividades políticas, salvo que estaba vinculado al Partido Radical Socialista. En 1931 desempeñó el cargo de gerente de Prensa Española, en Madrid, y estuvo afiliado a la logia Silencio, de esa capital. Al finalizar la guerra civil, Climent Terrer fue detenido por las autoridades franquistas; se retractó, y a pesar de ser un destacado masón, tan sólo se le inhabilitó. Su expediente se conserva en el Archivo Histórico Nacional de Salamanca.

La traducción y edición que Climent Terrer preparó de las Constituciones de James Anderson tienen un valor añadido, puesto que la publicación estaba más que justificada con dar a conocer las Constituciones que marcan el inicio de la moderna masonería. Sin embargo, la obra que nos ocupa contiene además algunos textos de gran interés, tanto para los masones actuales de habla castellana como para quienes se interesen por el fenómeno iniciático y su historia. Climent incluyó en la edición una selección de fragmentos de textos antiguos de la masonería operativa que aún hoy no cuentan con una versión castellana completa. Nos referimos al manuscrito Regius, de circa 1390, ya citado, también al manuscrito Harleian, de 1670, ( ms. n 1942, depositado en el British Museum) así como a otra Old Charge, a la que da el nombre de Manuscrito Antiguo, fechado en 1686.

A estos landmarks hay que añadir varios escritos de autores anglosajones que nos dan sus respectivas interpretaciones de lo que son y significan las antiguas Marcas, esto es, los usos, costumbres, reglas y leyes de la antigua masonería, que son consideradas fundamentales, aunque los autores nunca se hayan puesto de acuerdo en su definición, clasificación y enumeración, como señala F. Climent.

Completa esta obra un texto de 1922, leído en una logia norteamericana, en la que se defiende la actuación de la masonería en la política de los países cuyos gobiernos no respetan las libertades, así como la formación de organizaciones masónicas internacionales, a imagen de la Asociación Masónica Internacional, con sede en Suiza, a la que estaba afiliada la masonería española.

En definitiva, esta edición es bastante más que las Constituciones de Anderson, pues da a conocer textos fundamentales de la masonería por entonces del todo ignorados en España, y que en la actualidad siguen siéndolo en gran parte. Es también, una muestra fidedigna de lo que fue la cultura masónica española del primer tercio del presente siglo. 


\section{Fuentes}

Boletín Oficial de la Masonería Regular de España 12 (15 de mayo de 1884): 6.

Contreras de Diego, Eduardo. Anuario Masónico Universal para el año de 1886. Madrid, 1885.

Boletín Oficial del Grande oriente Español 131 (11 de marzo de 1903): 43.

El Mallete 31 (15 de febrero de 1883): 1-2.

Historia General de la Orden Franmasónica. La Habana, 1883.

La Constitución de 1723 proyectada por J. Anderson... Edición y notas de Pere Sánchez Ferré. Barcelona: Ed. Alta Fulla, Barcelona, 1998.

Manual del Franc-Masón. Madrid, 1871.

\section{Bibliografía}

Clavel, F. T. B. Historia de la Francmasonería. Madrid: Ed. El Museo universal, 1984.

Cortijo, Esteban. Mario Roso de Luna. Diputación Prov. de Badajoz, 1992.

Ferrer Benimeli, José Antonio. Bibliografía de la masonería. Madrid: FUE, 1978.

Guénon, René. Études sur la Franc-maçonnerie et le Compagnonnage. París: Éd. Traditionelles, 1978.

Guénon, René. El Teosofismo. Barcelona: Ed. Obelisco, 1989.

Ligou, Daniel. Constitutions d'Anderson. París: Edimaf, 1992.

Sánchez Ferré, Pere. La maçoneria a la societat catalana del segle XX 1900-1947. Barcelona: Ed. 62, 1993. 